\title{
EFFECT OF FABRIC LAYERS ON WHITENESS AND YELLOWNESS INDICES OF SOME POLYESTER FABRICS WOVEN WITH DIFFERENT CONSTRUCTIONAL PARAMETERS
}

\author{
Mine Akgun \\ Engineering Faculty, Department of Textile Engineering, Uludag University, Gorukle Campus, Bursa, Turkey, \\ E-mail: akgunm@uludag.edu.tr
}

\begin{abstract}
:
This paper focuses on the assessment of whiteness indices (WI) changes that occurred in white polyester fabrics according to different fabric layers. Yellowness indices (YI) were also assessed with the WI of fabric samples. White polyester fabrics having different constructional parameters were used, the results showed that WI of polyester fabrics increased up to a certain layer of fabric depending on constructional parameters and compactness of fabric. After a certain layer, WI of fabrics remained almost constant or steeply decreased. YI changed in good relation with whiteness changes. The results showed that the suitable number of fabric layer could be determined for WI measurements according to the compactness and to the structural parameters of the fabric samples. The suitable choice of the fabric layers for whiteness measurement depended on fabric constructional properties and could be made by considering the certain layer number, which could be obtained at the point of the maximum value of whiteness.
\end{abstract}

\section{Keywords:}

Whiteness Indices, Yellowness Indices, Fabric Layers, Polyester Woven Fabric.

\section{Introduction}

Whiteness can be defined as an aspect of colour corresponding to a high luminosity and an absence of hue and greyness [1-4]. Numerous indices of whiteness exist to characterise whites $[2,5,6]$. In physical terms, a white surface is the one that reflects strongly $(>50 \%)$ throughout the visible spectrum. The higher and more uniform the spectral reflectance, the whiter is the appearance of the object. Geometrically, a white surface reflects diffusely in all directions. Mirrors, though reflect strongly throughout the visible spectrum, but only in one direction and hence, are not called white. The difference is that white materials have high-scattering coefficient as well as lowabsorption coefficients [4]. White is called an achromatic colour and is characterised by constant absorption between 400 and $700 \mathrm{~nm}$ [7]. Experience shows that when a white is slightly pinkish or greenish, the eye easily classes the examined surface in the category of 'non-whites'. On the other hand, it is much more difficult to find agreement when the whites studied are on the blue-yellow axis (axis $b^{*}$ ). It is for this reason that certain whiteness formulae give an important weight to the notion of blue-yellow [2].

Instrumental evaluation of whiteness is generally carried out by a two-step method: the measurement of spectral reflectance of samples; and the evaluation of whiteness from the resultant data by various graphical or numerical methods [8-10]. In order to evaluate whiteness quantitatively, numerous whiteness formulae have been created in an attempt to remove the reliance on visual estimations [8-10]. In 1979, the CIE (Commission Internationale de l'Eclairage) recommended a whiteness index based on research by Ganz [9]. This formula was incorporated into an ISO standard in 1987 (ISO 11475, ISO/DIS 11476) and an AATCC (American Association of Textile Chemists and Colorists) standard two years later (AATCC 110). This formula calculates whiteness, $W$, and is based on illuminant D65 and either standard observer [11].

Under the CIE1964 standard observer $\left(10^{\circ}\right)$ and D65 illuminant viewing conditions, the CIE whiteness indices (WI) is shown by eq. (1) [10]:

$$
W=Y+800(x n-x)+1700(y n-y)
$$

where $Y$ shows the lightness and $x, y$ and $x n, y n$ are the chromaticity coordinates of the sample and the illuminant, respectively. The CIE WI are restricted by eq. (2) [10]:

$$
40<W<(5 Y-280)
$$

Consequently, the white samples that satisfy the aforementioned limitations could be evaluated by the CIE whiteness formula $[9,10,12-15]$. The validity of the CIE whiteness index in comparison to visual evaluations has been reported by different researchers $[10,13,15]$.

The CIE formula represents a very useful harmonisation of the methods of evaluating whiteness, as none of them shows any real superiority in the current test conditions. It is complicated by the condition $40<W<(5 Y-280)$, which limits its application by not allowing the use of results outside these limits of whites $[1,2]$. 
A white textile can rarely be compared to a sheet of white paper or a flat surface, which is painted white. A textile surface is often highly structured, permeable to light and composed of different materials. Such highly structured surfaces can mean that difficulties arise when measuring the colour or whiteness of such a material [2].

Steen et al. [2] studied the instrumental measurement of whiteness related specifically to structured textiles. Both brightened and unbrightened white textiles have been investigated. A method of controlling the acceptability of whites is proposed specifically for highly structured textiles. The distribution of the measurements for a sample of a white textile is more dispersed, the more the sample is structured.

The aim of this study is to assess the effect of different fabric layer numbers on $\mathrm{WI}$ of white (unbrightened) polyester fabrics woven with different constructional parameters and to determine the optimum fabric layer number during the spectrophotometric measurements.

\section{Experimental part}

White polyester woven fabrics with different constructional parameters (weft yarn density, weft yarn count/filament number and weave pattern) were used. The fabrics were woven under controlled weaving conditions in order to obtain the exact constructional properties. After weaving, woven fabrics were pre-treated (washed with a non-ionic agent $(2 \mathrm{~g} / \mathrm{l})$ at $60^{\circ} \mathrm{C}$ for
30 minutes and later stentered without tension at $180^{\circ} \mathrm{C}$ for 60 seconds) under mill conditions. Constructional parameters of the fabrics are given in Table 1. Weave patterns were selected as plain, twill (1/3) and sateen (1/7). Twill and sateen fabrics were weft faced ones. Fibres of the yarns had round cross-sectional shapes and they were semi-dull fibres. Warp yarn properties and warp densities were the same for the corresponding subgroups. In the first group of fabrics, warp yarns were textured yarns; in the second group of fabrics, warp yarns were spun (350 $\mathrm{T} / \mathrm{m}, \mathrm{Z}$ ) from continuous filament polyester. Weft yarn properties were different from each other in the corresponding sub-groups. These differences were weft yarn density, weft yarn count, weft yarn filament number/fineness. The weft yarns were textured polyester yarns. Fabric samples did not contain any fluorescent whitening agents.

\section{Measurements of $\mathrm{Wl}$ and yellowness indices}

All the measurements that were related to the calculations were carried out on a Macbeth Reflectance Spectrophotometer (MS 2020+) between 400-700 nm under a D65/10 illuminant and in Specular Component Included mode. Spectrophotometric measurements were performed at six different fabric layer numbers $(1,2,3,4,8$ and 16). The $\mathrm{WI}$ and yellowness indices $(\mathrm{YI})$ of fabrics were measured for different fabric layer numbers according to AATCC Test Method 110 [16] and. to ASTM (American Society for Testing and Materials) E 313 standard [17], respectively. Samples were prepared as four replicas for the spectrophotometric measurements. Four

Table 1. Constructional parameters of the white polyester fabrics.

\begin{tabular}{|c|c|c|c|c|c|c|}
\hline $\begin{array}{l}\text { Fabric } \\
\text { group }\end{array}$ & $\begin{array}{c}\text { Warp count } \\
\text { [denier/filament] }\end{array}$ & $\begin{array}{l}\text { Warp density } \\
\text { [thread } / \mathrm{cm}]\end{array}$ & $\begin{array}{l}\text { Weft count } \\
\text { [denier/ } \\
\text { filament] }\end{array}$ & $\begin{array}{l}\text { Weft density } \\
\text { [thread/cm] }\end{array}$ & $\begin{array}{c}\text { Mass per unit area } \\
{\left[\mathrm{g} / \mathrm{m}^{2}\right]}\end{array}$ & $\begin{array}{l}\text { Fabric } \\
\text { weave }\end{array}$ \\
\hline \multirow{9}{*}{$1^{\text {st }}$} & \multirow{3}{*}{$75 / 36$} & \multirow{3}{*}{60} & \multirow{3}{*}{$\begin{array}{c}75 / 36 \\
(2.08 \mathrm{dpf})\end{array}$} & 27 & 86,00 & \multirow{3}{*}{ Plain } \\
\hline & & & & 32 & 90,00 & \\
\hline & & & & 37 & 95,67 & \\
\hline & \multirow{3}{*}{$75 / 36$} & \multirow{3}{*}{60} & \multirow{3}{*}{$\begin{array}{c}75 / 36 \\
(2.08 \mathrm{dpf})\end{array}$} & 27 & 85,77 & \multirow{3}{*}{ 1/3 Twill } \\
\hline & & & & 32 & 90,00 & \\
\hline & & & & 37 & 95,44 & \\
\hline & \multirow{3}{*}{$75 / 36$} & \multirow{3}{*}{60} & \multirow{3}{*}{$\begin{array}{c}75 / 36 \\
(2.08 \mathrm{dpf})\end{array}$} & 27 & 85,68 & \multirow{3}{*}{ 1/7 Sateen } \\
\hline & & & & 32 & 90,00 & \\
\hline & & & & 37 & 95,00 & \\
\hline \multirow{8}{*}{$2^{\text {nd }}$} & \multirow{4}{*}{$150 / 36$} & \multirow{4}{*}{35} & \multirow{4}{*}{$\begin{array}{c}70 / 72 \\
(0.97 \mathrm{dpf})\end{array}$} & 18 & 94,46 & \multirow{4}{*}{ Plain } \\
\hline & & & & 22 & 97,35 & \\
\hline & & & & 26 & 102,54 & \\
\hline & & & & 28 & 104,89 & \\
\hline & \multirow{4}{*}{$150 / 36$} & \multirow{4}{*}{35} & \multirow{4}{*}{$\begin{array}{c}150 / 96 \\
(1.56 \mathrm{dpf})\end{array}$} & 18 & 105,78 & \multirow{4}{*}{ Plain } \\
\hline & & & & 22 & 112,23 & \\
\hline & & & & 26 & 122,04 & \\
\hline & & & & 28 & 130,12 & \\
\hline
\end{tabular}


measurements were made on each replica with a sample rotation of $90^{\circ}$ and $\mathrm{WI}$ and $\mathrm{YI}$ of a sample was calculated by using total 16 measurements.

\section{Measurements of fabric mass per unit area}

Fabric mass per unit area of woven fabric is an important parameter that affects most of its physical properties (i.e. compactness of fabric). Therefore, fabric mass per unit area of fabrics were measured according to the ASTM D3776-96 [18]. The fabrics were conditioned under standard laboratory conditions [19] at a temperature of $20 \pm 2^{\circ} \mathrm{C}$ and relative humidity of $65 \pm 2 \%$.

\section{Statistical evaluation of test results}

Factor analysis of variance was used to evaluate the effect of weft density, weft yarn count/filament number and weave pattern on fabric $\mathrm{WI}$ according to fabric layer number. Mean values were compared according to Student-Newman-Keuls (SNK) test at a 0.05 significance level using a statistical package program. Statistical results of SNK for different factor numbers are summarised in Table 2.

\section{Results and discussion}

The changes of $\mathrm{Wl}$ according to fabric layers were presented for the first and the second group of fabrics in Figures 1 and 2 , respectively. The first group of fabrics was woven from the same yarn count and filament numbers in weft direction (75/36 denier/filament [dpf]). This group of fabrics differed from each other in weft yarn densities $(27 ; 32$ and 37 thread/cm) and in fabric weave patterns (plain; $1 / 3$ twill and1/7 sateen). The second group of fabrics was woven from different yarns in weft direction. The yarns differed from each other both in yarn counts and in yarn filament numbers (dpf number; 70/72 and $150 / 96)$. The $70 / 72 \mathrm{dpf}$ yarn could be considered as polyester yarn with microfibre (micro denier) fibre fineness ( 0.97 dpf) and 150/96 dpf yarn could be considered as polyester yarn with conventional fibre fineness ( 1.56 dpf). Also, the fabrics differed from each other in weft densities $(18 ; 22 ; 26$ and 28 thread $/ \mathrm{cm})$. All the fabrics in this group had plain weave pattern.

When all the changes in WI were considered, it could be stated that direct relations could not be obtained among constructional parameters of fabrics and WI. The relation phenomenon between physical structure and $\mathrm{WI}$ was considered from the view point of fabric layers of woven fabrics.

Figures 1 and 2 showed that WI of all fabrics increased up to a certain fabric layer for the first and the second group of fabrics (eight layers and three layers, respectively). After eight fabric layers, WI of the first group fabrics (Figure 1) slightly decreased in plain weave fabrics, whereas the WI were almost the same in fabrics that had high yarn float length and float numbers (1/3 twill and $1 / 7$ sateen weave patterns). After three fabric layers, $\mathrm{WI}$ of the second group fabrics with plain pattern (Figure 2) steeply decreased as fabrics layers increased.

Statistical results considering the effect of fabric constructional parameters (weft density, weft yarn count, weft yarn filament number/fineness and weave pattern) on fabric WI according to fabric layer number are presented in Table 2 for the first and the second group of fabrics, respectively. Statistical results showed that the effects of constructional parameters, such as weft density and weft yarn count/filament number, on WI changed according to fabric layer number.

Statistical results, which explained the effects of weft yarn density and weave pattern on fabric $\mathrm{WI}$ of the first group of fabrics, are presented in Table 2. Results of fabric samples with

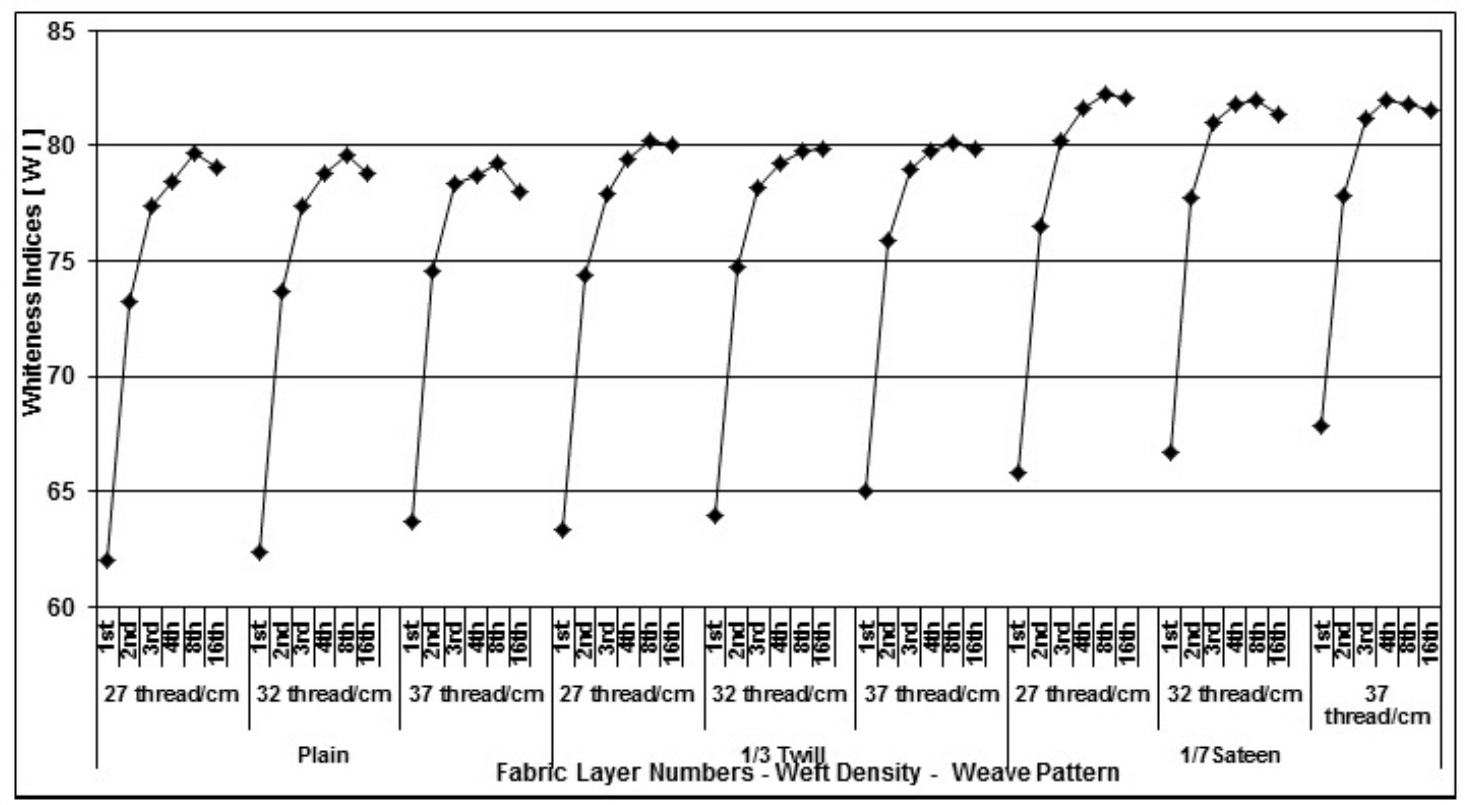

Figure 1. Changes in the first group of fabrics' whiteness indices according to the fabric layers. 


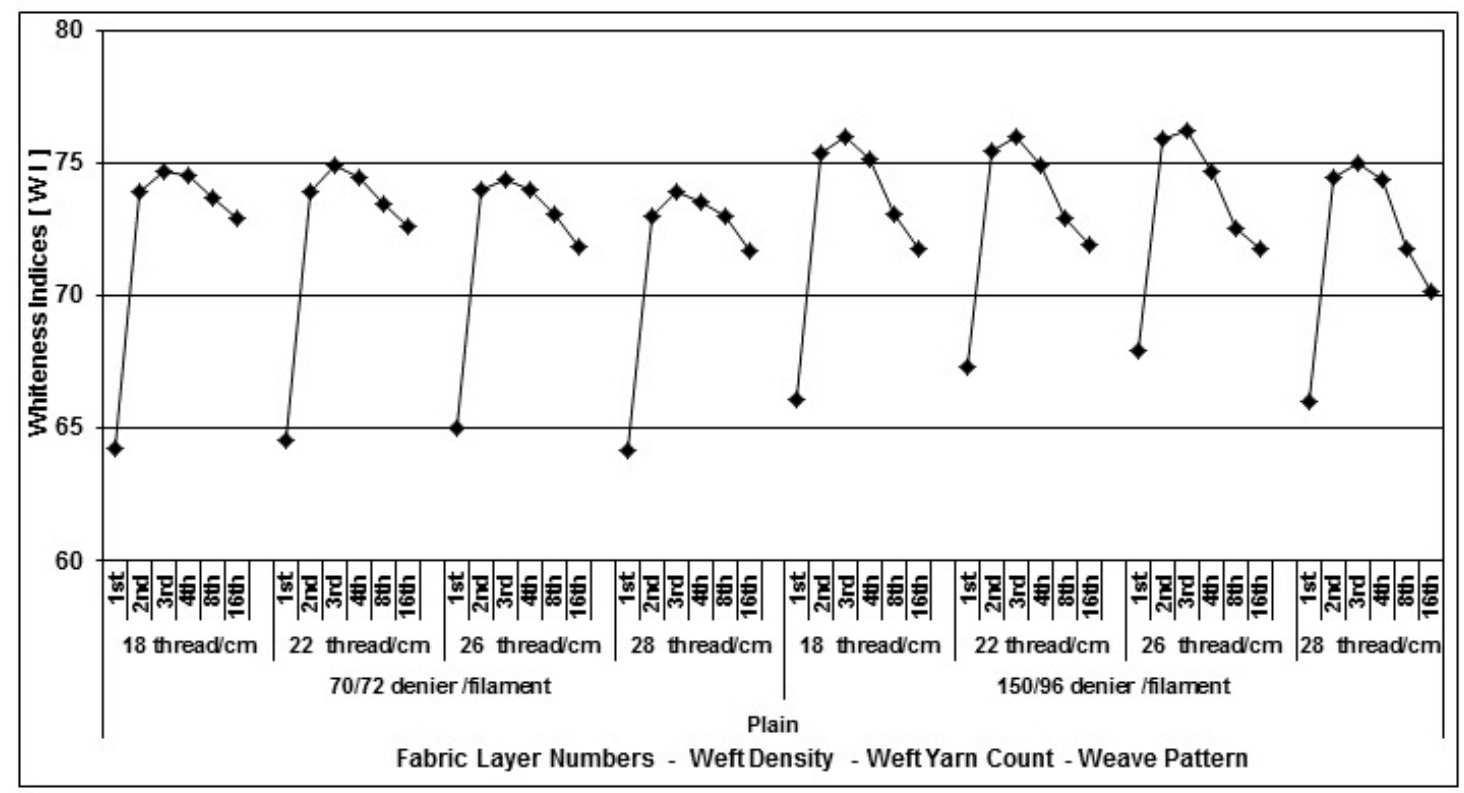

Figure 2. Changes in the second group of fabrics' whiteness indices according to the fabric layers.

Table 2. Changes of the whiteness indices' SNK results of the first and the second group of fabrics depending on fabric layer numbers.

\begin{tabular}{|c|c|c|c|c|c|c|c|c|}
\hline \multirow{4}{*}{$\begin{array}{l}\text { Fabric } \\
\text { group }\end{array}$} & \multirow{4}{*}{ Factors } & \multirow{4}{*}{ Treatment } & \multicolumn{6}{|c|}{ Fabric whiteness indices [WI] } \\
\hline & & & \multicolumn{6}{|c|}{${ }^{\text {aRank }}$} \\
\hline & & & \multicolumn{6}{|c|}{ Fabric layer numbers } \\
\hline & & & $1^{\text {th }}$ & $2^{\text {nd }}$ & $3^{\text {rd }}$ & $4^{\text {th }}$ & $8 t^{h}$ & $16^{\text {th }}$ \\
\hline \multirow{2}{*}{$1^{\text {st }}$} & $\begin{array}{c}\text { Weft density } \\
{[1 / \mathrm{cm}]}\end{array}$ & $\begin{array}{l}1(27) \\
2(32) \\
3(37)\end{array}$ & $\begin{array}{l}3 \\
2 \\
1\end{array}$ & $\begin{array}{l}3 \\
2 \\
1\end{array}$ & $\begin{array}{l}3 \\
2 \\
1\end{array}$ & $\begin{array}{l}3 \\
2 \\
1\end{array}$ & $\begin{array}{l}1 \\
2 \\
3\end{array}$ & $\begin{array}{l}1 \\
2 \\
3\end{array}$ \\
\hline & Weave pattern & $\begin{array}{c}1 \text { (plain ) } \\
2 \text { (twill 1/3) } \\
3 \text { (sateen 1/7) }\end{array}$ & $\begin{array}{l}3 \\
2 \\
1\end{array}$ & $\begin{array}{l}3 \\
2 \\
1\end{array}$ & $\begin{array}{l}3 \\
2 \\
1\end{array}$ & $\begin{array}{l}3 \\
2 \\
1\end{array}$ & $\begin{array}{l}3 \\
2 \\
1\end{array}$ & $\begin{array}{l}3 \\
2 \\
1\end{array}$ \\
\hline \multirow[t]{2}{*}{$2^{\text {nd }}$} & $\begin{array}{l}\text { Weft density } \\
{[1 / \mathrm{cm}]}\end{array}$ & $\begin{array}{l}1(18) \\
2(22) \\
3(26) \\
4(28)\end{array}$ & $\begin{array}{l}3 \\
2 \\
1 \\
4\end{array}$ & $\begin{array}{l}3 \\
2 \\
1 \\
4\end{array}$ & $\begin{array}{l}3 \\
2 \\
1 \\
4\end{array}$ & $\begin{array}{l}1 \\
2 \\
3 \\
4\end{array}$ & $\begin{array}{l}1 \\
2 \\
3 \\
4\end{array}$ & $\begin{array}{l}1 \\
2 \\
3 \\
4\end{array}$ \\
\hline & $\begin{array}{c}\text { Weft yarn count } \\
\text { [denier/filament number] }\end{array}$ & $\begin{array}{c}1(70 / 72) \\
2(150 / 96)\end{array}$ & $\begin{array}{l}2 \\
1\end{array}$ & $\begin{array}{l}2 \\
1\end{array}$ & $\begin{array}{l}2 \\
1\end{array}$ & $\begin{array}{l}1 \\
2\end{array}$ & $\begin{array}{l}1 \\
2\end{array}$ & $\begin{array}{l}1 \\
2\end{array}$ \\
\hline
\end{tabular}

${ }^{a}$ The rank is presented from the highest whiteness indices to the lowest whiteness indices.

SNK: Student-Newman-Keuls.

high weft density showed that the highest WI were obtained at $1,2,3$ and 4 fabric layers, whereas results of fabric samples with low weft density showed that the highest WI were obtained at 8- and 16-times layered fabrics. The effect of weave pattern on fabric WI did not statistically change according to the fabric layer number. The statistical results presented in Table 2 showed that $\mathrm{WI}$ increased as weave patterns changed from plain to sateen. Also, fabrics with long yarn float lengths and float numbers had the highest WI.

Statistical results considering the effect of weft yarn density and weft yarn count/filament number on fabric WI of the second group of fabrics showed that the effects of these factors on fabric WI changed according to fabric layers and this change depended on different factors related to the compactness of woven fabrics. In Table 2, fabric samples with 26 thread/cm weft density had the highest $\mathrm{WI}$ at 1,2 and 3 fabric layers, whereas fabric samples with low weft density $(18$ thread/cm) had the highest WI at 4-, 8- and 16-times layered fabrics. Fabric samples with the highest weft density (28 thread/cm) showed the lowest WI at all fabric layers.

Regarding yarn count and yarn filament number/fineness presented in Table 2, fabric samples with high weft yarn count and low filament fineness (conventional fibre fineness) showed the highest WI at 1, 2 and 3 fabric layers, whereas fabric samples with low weft yarn count and high filament fineness (micro denier fibre fineness) showed the highest $\mathrm{WI}$ at 4-, 8- and 16-times fabric layers. These results showed that the $\mathrm{WI}$ of fabrics could be changed depending on the compactness of fabrics. 
Fabric constructional parameters that are related to the compactness of woven fabrics are various, such as yarn density, yarn count, yarn filament fineness, yarn intersections (weave pattern) and mass per unit area, etc. The increase in yarn density, yarn filament number, yarn intersection number and mass per unit area would have resulted in more compact structured fabrics. These parameters (Table 1) were taken into consideration when the evaluation of SNK results of WI was presented in Table 2.

Fabric mass per unit area is a property of fabrics that relates the compactness of the fabrics by yarn density, yarn count/filament number and yarn intersections in fabric. For this reason, fabric mass per unit area enables us to deal with the compactness properties of fabrics. Fabric mass per unit area values were taken into consideration when the comparison of changes of the first and the second group of fabrics' WI were made according to the fabric layers. Results in Table 1 shows that fabric mass per unit area values of the second group of fabrics are higher than the first group of fabrics. In Figures 1 and 2, the decrease of $\mathrm{WI}$ of the first and the second group of fabrics was observed at 8- and 3-times fabric layers, respectively. This could confirm the decrease of fabric WI observed at lower fabric layers as the fabric compactness increased.

The results showed that $\mathrm{WI}$ of polyester fabrics increased up to a certain fabric layer number. After this layer number, WI of fabrics remained almost unchanged or steeply decreased depending on compactness of fabrics. In order to investigate this observation, the relation phenomenon between $\mathrm{Wl}$ and fabric layers was considered from the view point of $\mathrm{Yl}$ according to six different fabric layers.

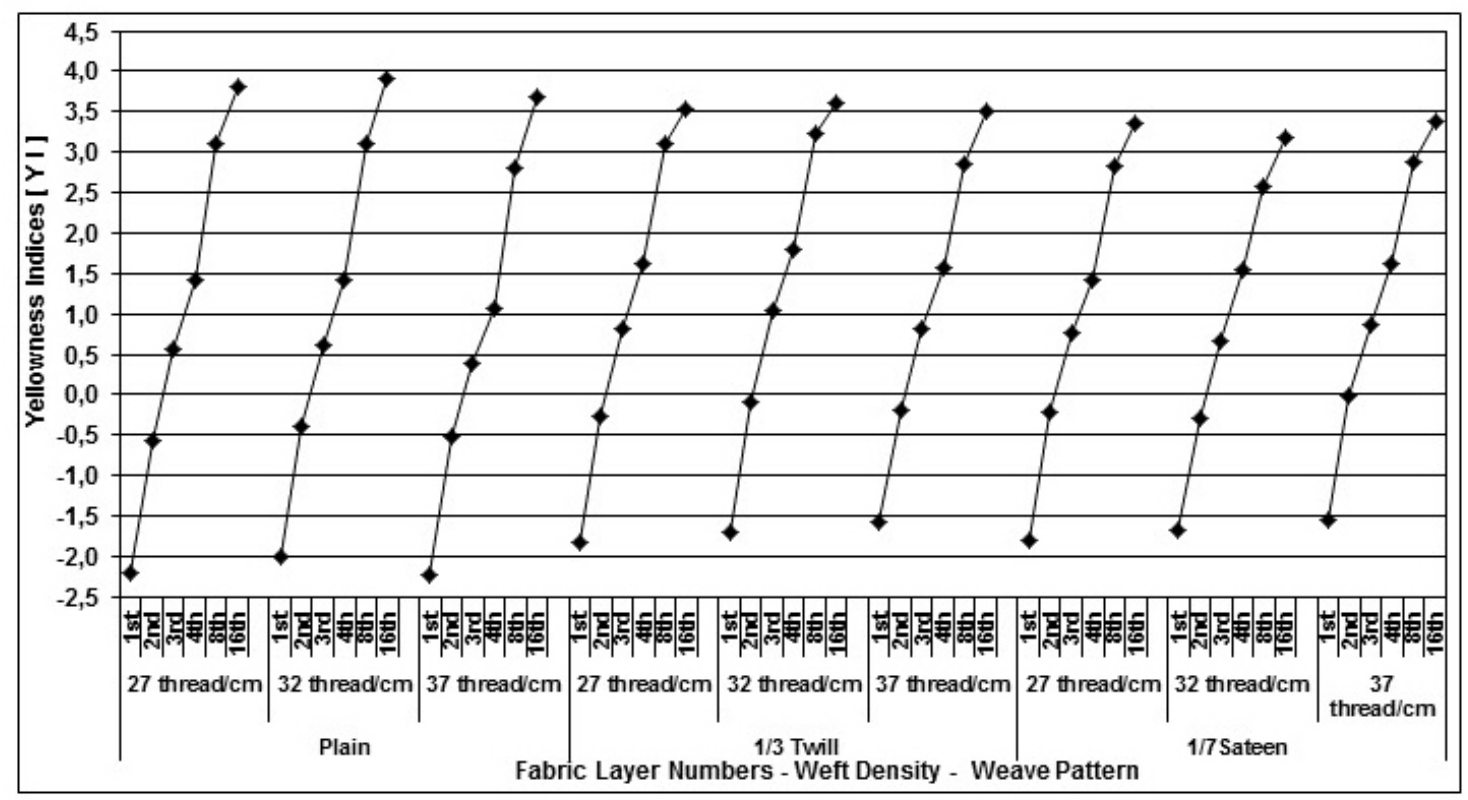

Figure 3. Changes in the first group of fabrics' yellowness indices according to the fabric layers.

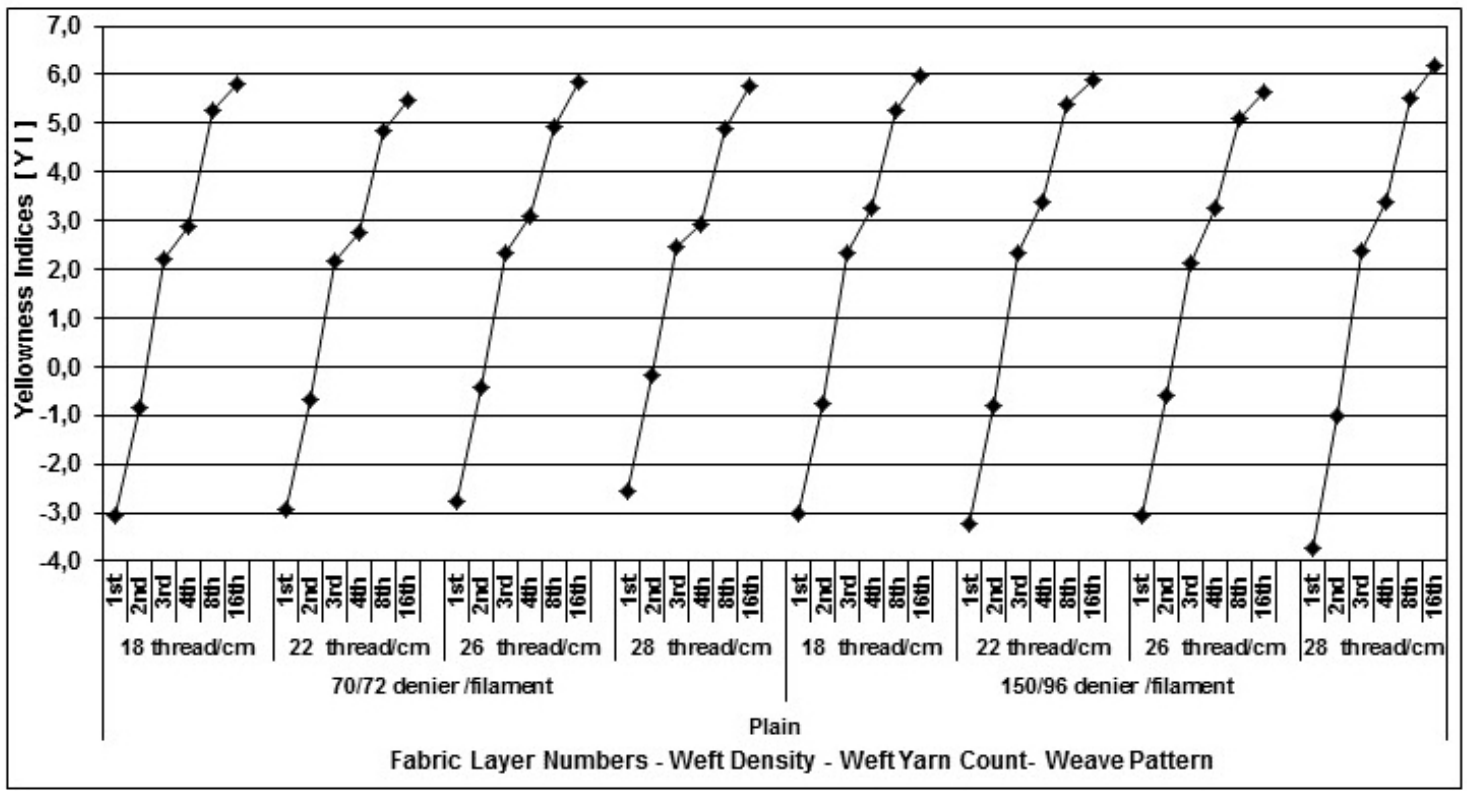

Figure 4. Changes in the second group of fabrics' yellowness indices according to the fabric layers. 
The relation between $\mathrm{YI}$ and fabric layers is presented in Figures 3 and 4 for the first and the second group of fabrics, respectively. Figures 3 and 4 show that $\mathrm{YI}$ of white polyester fabrics moved from negative values to positive values as fabric layers increased for the both group of fabrics. These results have confirmed that $\mathrm{WI}$ of polyester fabrics decreased (Figures 1 and 2) as $\mathrm{YI}$ increased according to increased fabric layers.

The decreases observed in WI after a certain layer of fabric indicated the effect of light trap phenomenon on reflectance measurements. Fabric layers constituted a bulk volume as the layers increased and the bulk volume in measurement port could have created a black area-shaped ring at the edge points of the measurement port, which acted as a light trap for reflected light.

YI results also supported these findings because $\mathrm{YI}$ values moved from negative values to positive values as fabric layers increased. Departure of $\mathrm{YI}$ values from negative to positive indicated the shade of the surfaces to change from blue to yellow. Formation of light traps could have changed the reflectance characteristics of the samples in the sample port.

YI changed steeply from negative values to positive values in all fabric samples as fabric layers increased. In Figure 4, where $\mathrm{YI}$ of plain fabric are presented, the results changed in a boarder range from negative to positive than the results presented in Figure 3. These changes were in parallel with the changes in $\mathrm{WI}$ presented in Figures 1 and 2. Higher $\mathrm{YI}$ caused lower WI when Figures $1-2$ and Figures $3-4$ were compared. Fabric layer numbers were closely related with $\mathrm{WI}$ and $\mathrm{YI}$ and it was observed that the decreases in WI after certain fabric layers resulted from the increases in $\mathrm{YI}$ at the corresponding layers.

The regular structure of a textile fabric and its relation to incident light determines its surface properties through its constructional properties. An increase of fabric layers could have the opposite effect on internal change of the regular structure of a fabric and its relation with incident light depending on the fabric tested. Internal change of the fabric structure due to excessive fabric layers during spectrophotometric measurement could have caused $\mathrm{YI}$ to increase. Furthermore, increase of compactness of fabrics could actually have increased the occurrence of these observations. Certain fabric layers according to fabric compactness must be determined in order to obtain intrinsic WI of white fabrics.

An overall discussion of Figures 1-2 showed that WI of fabrics changed considerably by changes in constructional parameters and the number of fabric layers applied during measurement. For a precise measurement of whiteness, reflectance measurements could be made using the layer numbers $(1,2,3,4,8$ and 16) and the layer number in which the highest WI were obtained could be recorded as the appropriate one. Optionally, the fabric layer number in which the highest WI had been obtained could be stated when reporting the results.

\section{Conclusions}

Effects of fabric layers on $\mathrm{WI}$ and $\mathrm{YI}$ of polyester fabrics were reported in accordance with fabric constructional parameters. The results showed that $\mathrm{WI}$ of polyester fabrics increased up to a certain layer of fabric. After the certain layer, WI of fabrics remained almost constant or steeply decreased depending on constructional parameters and compactness of fabrics. The decrease in WI was observed more in compact-structuredfabrics (high yarn density, high yarn filament number, high yarn intersections and high mass per unit area) at lower fabric layers than in loose-structured fabrics (low yarn density, low yarn filament number, low yarn intersections and low mass per unit area).. WI and $\mathrm{YI}$ changed in relation to each other depending on fabric constructional properties and fabric layer numbers. For this reason, to assess WI of woven fabrics, a suitable fabric layer number must be considered according to fabric constructional parameters and fabric compactness by using test methods prior to final measurement.

\section{References}

[1] Sève, R.: Physique de La Couleur: de L'apparence Colorée à La Technique Colorimétrique, Masson, Paris, p.333, 1996.

[2] Steen, D., Dupont, D.: Control of Structured White Textiles. Coloration Technology, Vol.119, pp.205-2011, 2003.

[3] Wyszecki, G., Stiles, W.S.: Color Science: Concepts and Methods, Quantitative Data and Formulae, 2nd edition, John Wiley, New York, p.950, 1982.

[4] Choudhury, A.K.R.: Textile Preparation and Dyeing, Science Publishers, USA, p.834, 2006.

[5] Sève, R.: A Bibliography on Whiteness, Die Farbe, Vol. 26, pp.89-104, 1979.

[6] Sève, R.: First AIC Meeting, Stockholm, Sweden, p.335, 1969.

[7] Zollinger, H.: Color Chemistry, Syntheses, Properties, and Applications of Organic Dyes and Pigments, 3rd edition, Wiley-VCH, p.637, 2003.

[8] Choudhury, K.R.: Modern Concepts of Color and Appearance, Enfield: Science Publishers Inc., p. 340, 2000.

[9] Ganz, E.: Whiteness Formulas: A Selection, Applied Optics, Vol. 18, pp.1073-1078, 1979.

[10] Jafari, R., Amirshahi, S.H.: Variation in the Decisions of Observers Regarding the Ordering of White Samples. Coloration Technology, Vol.124, pp.124-131, 2008.

[11] Berns, R.S.: Bilmeyer and Saltzman's Principles of Color Technology, 3rd edition, John Wiley \& Sons, New York, p.247, 2000.

[12] McDonald, R.: Color Physics for Industry, 2nd edition, SDC, Bradford, p.202, 1997.

[13] Uchida, H.: A New Whiteness Formula, Color Research and Application, Vol.23, pp.202-209, 1998.

[14] Amirshahi, S.H., Agahian, F.: Basis Functions of the Total Radiance Factor of Fluorescent Whitening Agents, Textile Research Journal, Vol.76, pp.197-207, 2006.

[15] Jafari, R., Amirshahi, S.H.: A Comparison of the CIE and UCHIDA Whiteness Formulae as Predictor of Average Visual Whiteness Evaluation of Textiles, Textile Research Journal, Vol.77, pp.756-763, 2007. 
[16] AATCC Technical Manual, AATCC Test Method 110; “Whiteness of Textiles", Vol.75, pp.373-379, 2000.

[17]Annual Book of ASTM Standards, ASTM E 313-10; "Standard Practice for Calculating Yellowness and Whiteness Indices from Instrumentally Measured Color Coordinates", Vol. 06.01, West Conshohocken, PA, USA, 2010.
[18] Annual Book of ASTM Standards, ASTM D3776-96; Standard Test Methods for Mass per Unit Area (Weight) of Fabric, Vol. 07.01, West Conshohocken, PA, USA, 2011.

[19] ASTM D1776-08. Standard Practice for Conditioning and Testing Textiles, 2009. 